\title{
Socio-Demographic Factors Contributing to the Productivity in Paddy Farming: A Case Study
}

\author{
A. N. Siriwardana and L.N.A.C. Jayawardena ${ }^{1 *}$ \\ Postgraduate Institute of Agriculture \\ University of Peradeniya \\ Sri Lanka
}

\begin{abstract}
According to 2010 statistics, paddy cultivation had been the livelihood of more than 1.8 million farm families in Sri Lanka. The annual rice (Oryza sativa L.) production of 2.1 million tons in 1980 had increased to 4.3 million tons in 2010. Paddy farmers are mutually benefitted from group activities. This study examined the sociodemographic factors contributing to the success of paddy farmers in the Dry Zone of Sri Lanka with a focus on the innovation and adoption of new practices, farming experience, knowledge sharing and team behaviour among farmers. Their perceptions about farming as a career, productivity, and profitability in paddy farming were analyzed. Impact of gender on paddy farming practices was examined. Sixty three paddy farmers (32 males, and 31 females) were selected for the study from Polpithigama Divisional Secretariat area based on stratified random sampling. Mann-Whitney test, Wilcoxon rank-sum test, Correlation, and Chi-square tests were used for inferential analysis of data along with descriptive analysis. Knowledge sharing behaviour in farming correlated strongly with the respondents' perception of farming as a career. Knowledge sharing correlated moderately with their farming experience. Innovation and adoption of new practices was the major contributing factor in the productivity of paddy farming. Significant differences were observed between gender and farming practices, with male farmers recording superior performances over female farmers in many farming practices.
\end{abstract}

Keywords: Paddy farming, gender, knowledge sharing, group work, productivity

\section{INTRODUCTION}

The importance of farming increases with the global population predicted to reach nearly 9 billion by 2050 amidst a falling ratio of arable land to population. As per the Food and Agricultural Organisation (FAO), world`s total agricultural land area of 4.93 billion hectares is nearly $38 \%$ of the world's total land area. Asia contributes to almost $90 \%$ of the world's rice production. China, India, Vietnam, Burma, Indonesia, Bangladesh, and Sri Lanka are the major rice producing countries in Asia (FAO, 2012). The agricultural contribution to Sri Lankan economy was nearly $11.9 \%$ of GDP. About $32.7 \%$ Sri Lankan workforce had been involved in agricultural sector. Sri Lankan agriculture sector is dominated by smallholders, with over $64 \%$ of the farming families cultivating holdings of less than 0.8 hectares (Central Bank, 2010).

\footnotetext{
1 Department of Agriculture Extension, Faculty of Agriculture, University of Peradeniya, Sri Lanka.

Corresponding author: chandanacj@yahoo.com
} 


\section{Paddy Cultivation}

Rice is the staple food of the inhabitants of Sri Lanka. Paddy is cultivated mostly as a wetland crop in all the districts. Total land devoted for paddy is estimated to be about 708,000 Hectares (Central Bank, 2011). Sri Lankan agricultural sectors major contribution comes from the paddy sector. Paddy cultivation is the livelihood of more than 1.8 million farm families in Sri Lanka. They had produced 2.1 million tons of rice in 1980, and this has been increased to 4.3 million tons in 2010 (Central Bank, 2010).

\section{Farmer Groups}

Farmers gain mutual benefits from group activities in paddy cultivation. Kreitner et al. (1999) define a team as a 'small group with complementary skills who hold themselves accountable for common purpose, goals, and approach'. Group is a stage where members meet and negotiate personal interests. Some members try to obtain power and status through groups and organizations (Pretty \& Word, 2001). Farmer groups reduce transaction costs, improve marketing facilities, reduce cost of cultivation, and facilitate other services (Choupkova \& Bjornskov, 2002). Other benefits of farmer groups are; initiating and establishing culture of cooperation and coordination for their own benefits (Putnam, 1995), conducting collective actions to overcome common problems (Bebbington, 1996), improving resource management strategies resulting in growth of local market and rural economy (Bebbington, 1996), developing networks among members and facilitate members to share ideas and find ways for mutual supports. Farmers' groups help extension agents to improve member farmers' knowledge and practical skills of agricultural technologies (Putnam, 1995). Entrepreneurial action is embedded in social interactions with other individuals (Sarason et al., 2006). Autio \& Wennberg (2010) revealed strong group-level effects on entrepreneurial behaviours. This was further confirmed by Jayawardena \& Abeyrathna (2013) in a study conducted in Sri Lanka. They observed a significant relationship between the group interaction level and entrepreneurial behaviour of farmers.

\section{Knowledge Sharing in Farming}

Knowledge and information are vital to rural farm development (Agnes and Rola, 2002). Fellow farmers were identified to be the mostly available source to the Sri Lankan farmers in sharing information. Wijekoon \& Jayawardena (2010) found positive significant relationships between the use of information sources and personal factors, viz. age, social participation, degree of exposure to mass media, innovativeness, and risk orientation. Farmers` adoption of the technologies examined are related to a number of socio-economic factors of which the occupation, sex and level of education are the ones affecting the adoption of the technologies significantly (Atibioke, 2012). Empirical findings suggest that farmers who grow larger quantities of vegetables are mostly males, more educated and older than other farmers. The objective of Integrated Pest Management (IPM) technique is to maximize pest control in terms of overall economic, social and environmental values. Since farmers are the final decision-makers for the adoption of any technology, it is essential to identify their reaction and adoption level of various package of practices recommended for pest management in sericulture. However, not much attention has been paid to assessing the farmer's perception (Sakthivel et al., 2012). In this regard the practical implications faced by farmers have to be given due weightage. For example, lack of technical knowledge regarding the use of the practices recommended, and non-availability of bio control agents on time are common problems faced by farmers in the implementation of IPM (Reddy, 2006). 


\section{Scope of the Study}

Main purpose of this study was to examine the impact of socio-demographic factors of farmers on the viability of paddy farming. Study focus on examining the socio-demographic factors contributing to the success of paddy farmers in the Dry Zone of Sri Lanka. Specific attention was paid on analysing the innovation and adoption of new practices, farming experience, knowledge sharing, and team behaviour among farmers. Farmers' perceptions about paddy farming as a career, and the impact of gender difference to paddy farming practices were also focussed.

\section{METHODOLOGY}

\section{Sample Design}

Polpithigama Divisional Secretariat (DS) area in Kurunegala District of Sri Lanka was selected for the study. This DS area was selected to represent a dry zone farming community based on an exploratory study with the community leaders and government agriculture instructors. Balagolla, Indigolla, Herathgama and Saliyagama Grama Niladari (GN) Divisions of Polpithigama DS area were selected purposively based on the paddy cultivation practices and production. Paddy cultivation farmers' registration lists accessed through the Govijana Sewa Kendra was the sampling frame of the study. Accordingly, study population consisted of the paddy cultivation farmers in the Polpithigama DS area. A paddy farmer involved in farming in the DS area was the sampling unit. Sixty three (63) paddy farmers (32 males, and 31 females) were selected for the study from the Polpithigama DS area based on stratified random sampling (strata were gender, and farming experience).

\section{Data Collection and Analysis}

Data collection was conducted using an interview schedule. Interview schedule consisted of research constructs on knowledge sharing using a scale of eight statements modified from Zheng (2005), team behaviour (Poropat \& Jone, 2009), farmers perception of the nature of farming practices as a career ( 5 items scale developed by the authors by modifying the task demands scale of Felfe et al. , 1994), and the innovation and adoption of farming practices. Qualitative as well as quantitative data were collected; both primary as well as secondary data were used. Secondary data were used to supplement the findings. Key Informant Discussions (KID) was used to strengthen the quantitative findings. Secondary data were collected using the publications of Sri Lanka Census and Statistics Department, Hector Kobbekaduwa Agrarian Research and Training Institute (HARTI), World Bank publications etc. Data analysis was conducted using the Statistical Package for Social Sciences (SPSS). Descriptive statistics along with frequency tables were used. Mann-Whitney test, Wilcoxon rank-sum test, Correlation and Chi-square tests were used for inferential analysis of data. Results obtained from the quantitative analysis were supported by the qualitative data obtained through discussions, interviews and observations. 


\section{RESULTS AND DISCUSSION}

\section{Socio-demographic Characteristics}

Polpithigama DS area belonged to rural, and intermediate climatic zone in Sri Lanka. Respondents included similar proportions of males and females farmers. Age distribution of the sample ranged from a minimum of 34 years to a maximum of 72 years. Mean age of the sample was 53.56 years (mean age of males being 50.81 years, and the mean age of females being 56.39 years). Farmers' level of education varied from no formal education up to GCE Advanced Level education. Majority (64\%) have completed grade 10, and the mean level of education of the respondents in the sample was above grade eight (mean of males was 8.41, and mean of females was 8.10). Accordingly, no disparity could be observed in the education level based on the gender of respondents. Greater majority $(87.3 \%)$ of the respondents were married.
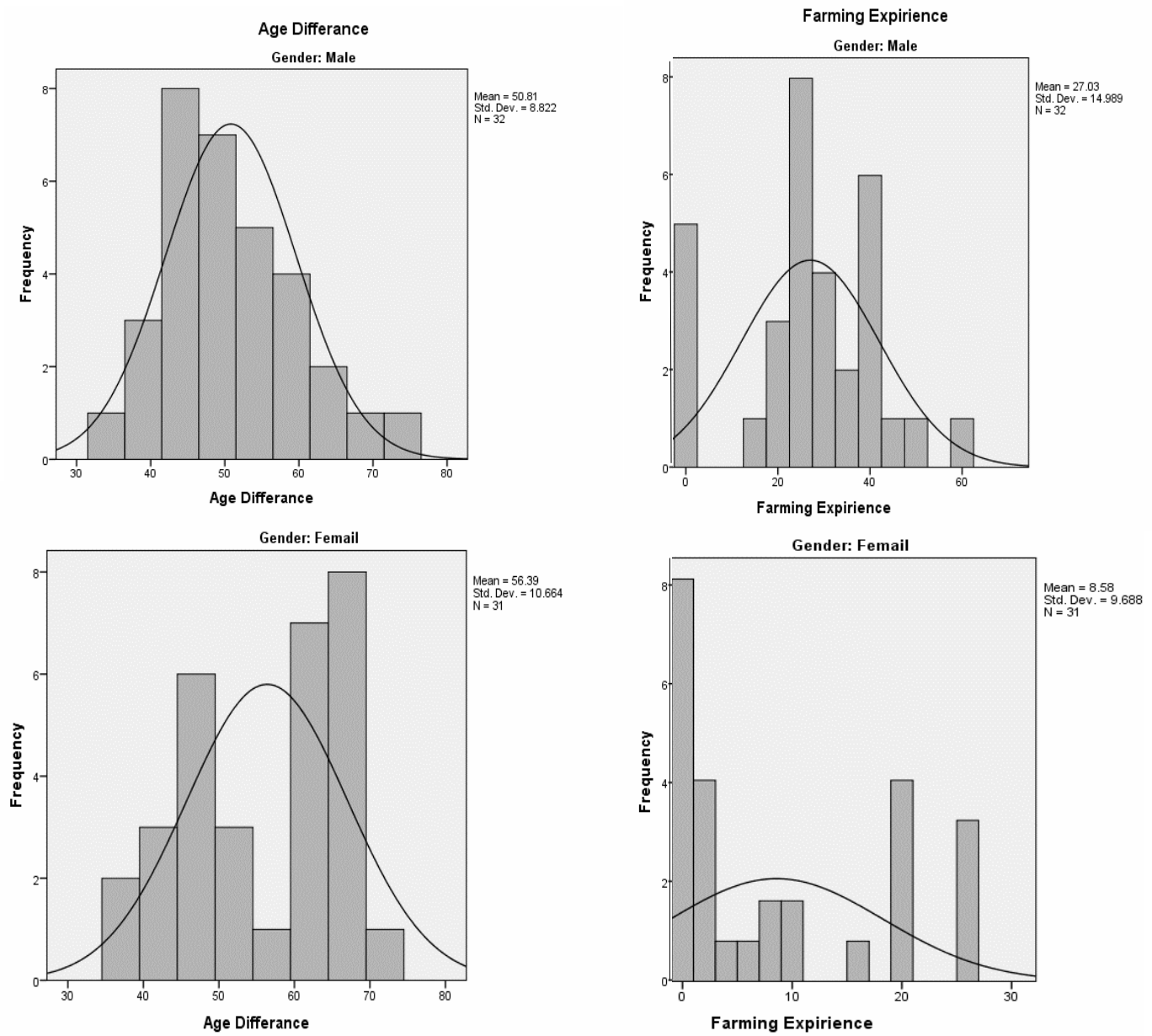

Fig. 1. Age, gender and farming experience

Source: Survey data of farmers in Polpithigama DS area 
Overall mean value of farming experience was 18 years. However, it varied vastly on gender (Figure1). Male farmers recorded a vastly experienced mean value of 27 years in farming, whereas females` farming experience recorded a mean value of 8.58 years.

\section{Team Work and Perception of Farming as a Career}

There was a significant difference between males and females in their perception of farming as a profession, and their success in farming practices (Mann-whittney u 362.500, Wilcoxon w 858.500, Z -1.847). Farmers' involvement in team work and co-operation also reported a significant difference based on their gender (Mann-whittney u 276.50, Wilcoxon w 772.50, Z -3.034). Female farmers reported a lower level of involvement in team behaviour, and cooperation during farming practices with a mean value of 24.92 , compared to the mean value of 38.86 recorded by the male's farmers.

\section{Knowledge Sharing among Farmers}

Knowledge Sharing (KS) was higher among male farmers (mean value of 34.02) compared to the female farmers (mean value of 29.92). There was a significant difference between the KS behaviour of male and female farmers (Mann-Whitney u 431.500, Wilcoxon w 927.500, Z -0.891).

\section{Table 1. Correlation of knowledge sharing with major variables}

\begin{tabular}{llc}
\hline & & Knowledge sharing \\
\hline \multirow{2}{*}{ Education level } & Correlation Coefficient & 0.181 \\
& Sig. (1-tailed) & 0.078 \\
& $\mathrm{~N}$ & 63 \\
Farming Experience & Correlation Coefficient & $\mathbf{0 . 2 0 9 ^ { * }}$ \\
& Sig. (1-tailed) & 0.050 \\
& $\mathrm{~N}$ & 63 \\
Perception of farming as & Sig. (1-tailed) & $\mathbf{0 . 5 3 5 ^ { * * }}$ \\
a career & $\mathrm{N}$ & 0.000 \\
& Sig. (1-tailed) & 63 \\
& $\mathrm{~N}$ & 0.000 \\
\hline
\end{tabular}

* Correlation is significant at the 0.05 level (1-tailed).

** Correlation is significant at the 0.01 level (1-tailed).

Source: Survey data of farmers in Polpithigama DS area

Correlations were sought using spearman`s correlation factor. Table 1 indicates significant correlations between the KS behaviour of farmers and their socio-demographic factors. Perception of farming as a career, and KS among farmers strongly correlated (correlation coefficient of 0.535). Farming experience also had an influence to the KS behaviour (with a correlation coefficient of 0.209 ). However, farmers' level of education did not correlate with their KS behaviour in farming.

\section{Innovation and Adoption of Practices}

There was a significant difference between male and female farmers in the innovation and adoption of new practices. Accordingly male (mean value of 33.33) farmers recorded a 
higher level of innovation, and adoption over female (mean value of 30.63) farmers. It was a significant difference (Mann-whittney u 453.500, Wilcoxon w 949.500, Z - 0. 598). There was also a significant difference in the extent of adoption (usage) of new practices based on gender. Male farmers recorded a higher extent of usage of new practices (mean value of 38.86). The extent of usage of new practices was low among females (mean value of 24.92). There was a significant difference in the extent of usage of the new practice based on gender (Mann-whittney u 276.50, Wilcoxon w 772.500, Z --3.034).

\section{Productivity and Profitability}

Though there were many differences of the farming practices between males and females, there was no significant difference between gender and average productivity in paddy farming. This may also be due to the participation of family members in paddy farming. KID's confirmed the active involvement of males in the family (relations, and neighbours at times) with farming in critical stages like land preparation, harvesting, and selling the produce. Liquored scale was used to measure the productivity and profitability as Very High $=4$, High=3, moderate $=2$, Low $=1$, no or very low $=0$. According to findings Male farmers recorded a higher productivity in paddy (mean value of 34.09), over females (mean value of 29.84). Males also recorded a superior profitability (mean value of 35.48), over females (mean value of 28.40). Contribution of the farming practices to profitability was analysed using regression modelling. Accordingly, the innovation and adoption of new practices was identified as the main factors (Figure 2). It had contributed by predicting the variation of the profitability by $72.40 \%(0.72)$ in the regression model (sig., 1-tail., 0.000). Farming experience was identified as the second contributing factor predicting the variability of profitability by $15 \%(0.15)$. Level of education has contributed $5 \%(0.05)$. Contribution of KS behaviour and other socio-demographic factors were identified as minimal.

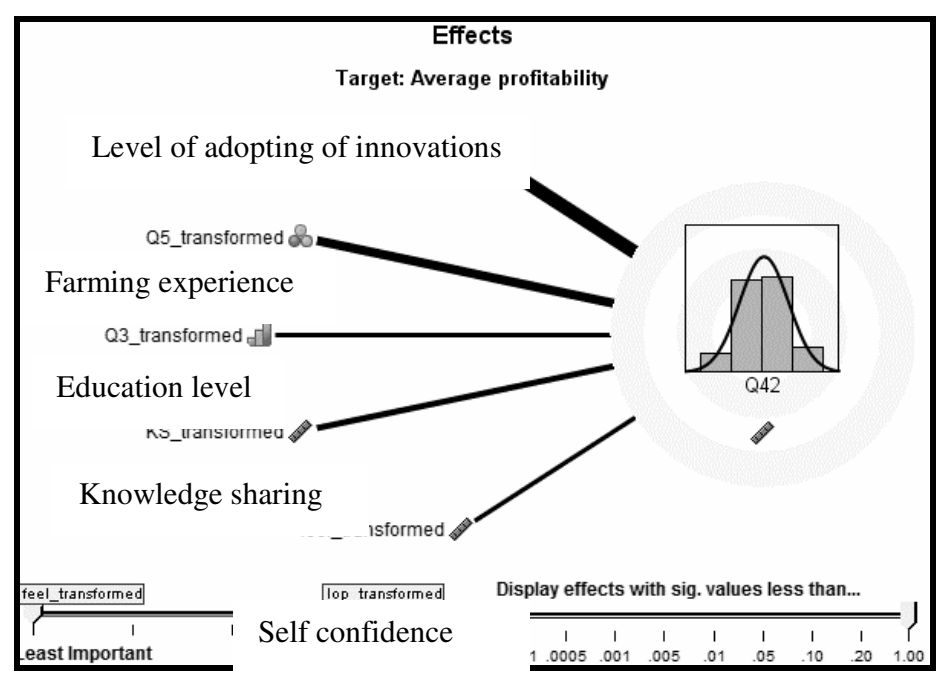

Fig. 2. Factors affecting on profitability

Source: Survey data among farmers of Polpithigama DS area 


\section{CONCLUSION}

Study has found significant differences between gender and farming practices. Male farmers recorded superior and significant performances on their perception of farming as a career, involvement in teamwork, knowledge sharing, and in innovation and adoption of practices. However, there was no significant difference in the productivity of paddy farming based on gender, though male farmers recorded superior productivity. This may also be due to the participation of family members in paddy farming. Knowledge sharing behaviour in farming correlated strongly with respondents' perception of farming as a career, and moderately with their farming experience. Innovation and adoption of new practices was the major contributing factor to the productivity of paddy farming. Farming experience also contributed in the productivity in farming.

Static nature of data is a serious weakness of contemporary management research, and this study also falls into this category as the data collection (interviewing and surveying) was carried out at a particular point in time during the year 2013. Also, the farmers` behaviours were assessed only based on their perceptions. A longitudinal research incorporating more objective data (i.e. profits, and profitability of farmers in actual terms, times spent for farming) would prove more insightful.

\section{REFERENCES}

Agnes, C. and Rola, S. (2002). Do farmer field school graduates retain and share what they learn? An investigation in Iloilo, Philippines. Journal of International Agricultural and Extension Education, 9(1), 65-76.

Atibioke, O.A., (2012). Effects of farmers' demographic factors on the adoption of grain storage technologies developed by Nigerian stored products research institute (NSPRI): A case study of selected villages in IlorinWest LGA of Kwara State, Research on Humanities and Social Sciences, 2(6),56-63.

Autio, E. and Wennberg, K. (2010). Social Attitudes and the Transition to Entrepreneurship, Summer Conference 2010, Imperial College, London Business School.

Bebbington, A. (1996). Organizations and Intensifications: Campesino Federations, Rural livelihoods and agricultural technology in the Amazon and World Development.

\section{Central Bank (2010). Economic and Social Statistics of Sri Lanka 2010 - Volume XXXII}

Central Bank (2011). Annual Report, Central Bank of Sri Lanka, Colombo.

Choupkova, J. and Bjornskov, C. (2002). Counting on social capital when easing agricultural credit constraints, Journal of Microfinance.

Felfe, J. Resetka, H.J. and Liepmann, D. (1994). Skalen zur Organisations diagnose (Scales for organizational diagnosis), FU-Berlin.

Food and Agricultural Organization (2012). FAO Statistical Yearbook 2012, Food and Agriculture Organization of the United Nations, Rome. 
Jayawardena, L.N.A.C., and Abeyrathne, H.R.M.P. (2013). Entrepreneurial behaviour and interactivity of farmer groups: A Sri Lankan case study, Eighth European Conference on Innovation and Entrepreneurship, Brussels, pp. 333-339

Kreitner, R., Kinicki, A. and Beulens, M. (1999) Organizational Behaviour (1 ${ }^{\text {st }}$ ed.). McGraw-Hill Publishing, London.

Poropat, A.E., and Jones, L.S. (2009). Development and validation of a unidimensional measure of Citizenship Performance. Journal of Occupational and Organizational Psychology, 82(4), 851-869. doi: 10.1348/096317908X374139

Pretty, T., and Word, H. (2001). Social capital and environment. World Development, 29(2).

Putnam, R. (1995). Bowling alone: America's declining social capital, Journal of Democracy, 6(1), 65-78.

Reddy, V.S. (2006). Knowledge and adoption of integrated pest management practices among vegetable growers of Gadag district in North-Karnataka, Unpublished M.Sc (Agri) Thesis, University of Agricultural Sciences, Dharwad, 46-47

Sakthivel, N., Kumaresan, P, Qadri, S.M.H., Ravikumar J., and Balakrishna, R. (2012), Adoption of integrated pest management practices in sericulture - A case study in Tamil Nadu. J.Biopes, Journal of Biopesticides, Vol. 5 Issue Sup, p212Vol. 5, 212 - 215.

Sarason, Y., Dean, T., and Dillard, J.F. (2006). Entrepreneurship as the nexus of individual and opportunity: A structuration view, Journal of Business Venturing, Vol. 21(3)

Wijekoon, W.M.N.D., and Jayawardena, L.N.A.C., (2010). Utilization of sources of Information for decision making of farmers - A Case Study, Peradeniya University Annual Research Sessions-2010, University of Peradeniya, Sri Lanka.

Zheng, W. (2005). The impact of organizational culture, structure, and strategy on knowledge management effectiveness, and organizational effectiveness, Unpublished doctoral dissertation, Graduate School of University of Minnesota, UMI no. 3180040. 